\title{
BMJ Open Knowledge and use of lactational amenorrhoea as a family planning method among adolescent mothers in Uganda: a secondary analysis of Demographic and Health Surveys between 2006 and 2016
}

\author{
Catherine Birabwa (D) , ${ }^{1,2}$ Pamela Bakkabulindi, ${ }^{1,3}$ Solomon T Wafula, ${ }^{1}$ \\ Peter Waiswa, ${ }^{1,4}$ Lenka Benova ${ }^{2}$
}

To cite: Birabwa C Bakkabulindi P, Wafula ST, et al. Knowledge and use of lactational amenorrhoea as a family planning method among adolescent mothers in Uganda: a secondary analysis of Demographic and Health Surveys between 2006 and 2016. BMJ Open 2022;12:e054609. doi:10.1136/ bmjopen-2021-054609

- Prepublication history for this paper is available online. To view these files, please visit the journal online (http://dx.doi. org/10.1136/bmjopen-2021054609).

$\mathrm{CB}$ and $\mathrm{PB}$ contributed equally.

Received 21 June 2021 Accepted 02 February 2022

Check for updates

(c) Author(s) (or their employer(s)) 2022. Re-use permitted under CC BY-NC. No commercial re-use. See rights and permissions. Published by BMJ.

For numbered affiliations see end of article.

Correspondence to Catherine Birabwa; cathybirabwa3@gmail.com

\section{ABSTRACT}

Objective To assess the level of knowledge and use of the lactational amenorrhoea method (LAM) among adolescents in Uganda between 2006 and 2016 using nationally representative data from Demographic and Health Surveys (DHS).

Design Cross-sectional design involving analysis of three DHS (2006, 2011, and 2016) in Uganda.

Setting The data collection took place in Uganda. The DHS are nationally representative surveys on a wide range of indicators including contraception knowledge and use. Participants A total of 1948 (2006), 2026 (2011) and 4276 (2016) adolescents (15-19 years) and 1662 (2006), 1666 (2011) and 3782 (2016) young women (20-24 years) were included.

Primary outcome measure Use of LAM among adolescents and young women with a live birth within 6 months before each survey.

Results In 2016, less than $1.0 \%$ (95\% Cl: $0.2 \%$ to $3.5 \%$ ) of eligible adolescents correctly used LAM, and $56.3 \%$ (95\% Cl: $48.8 \%$ to $63.6 \%$ ) were passively benefitting from LAM. The median duration of postpartum amenorrhoea (PPA) among adolescents in 2016 was 6.9 months, declining from 8.3 months in 2006. Compared with adolescents (56.7\%), eligible young women had higher knowledge of LAM (64.1\%) and higher median PPA duration (8.0 months) in 2016. The percentage of eligible adolescents who met the LAM criteria irrespective of whether they reported LAM use (were protected by LAM) decreased from $76.4 \%$ (95\% Cl: $66.5 \%$ to $84.0 \%$ ) in 2006 to $57.2 \%$ (95\% Cl: $49.5 \%$ to $64.6 \%$ ) in 2016 . More than $50.0 \%$ (95\% Cl: $49.2 \%$ to $63.8 \%$ ) of eligible adolescents were aware of LAM in 2016, increasing from $6.0 \%$ (95\% Cl: $2.5 \%$ to 13.8 ) in 2006.

Conclusion Despite increasing awareness of LAM, reported and correct use of LAM was low among adolescents who could benefit from this method in Uganda, and declining over time. Support for adolescents to harness the benefits of correct LAM use should be increased. Additional research is needed to better understand the dynamics of LAM use in adolescents,
Strengths and limitations of this study

- The study used data from three standardised nationally representative surveys in Uganda, thus findings are generalisable and comparable over time and across age groups.

- The study used various indicators to assess the knowledge and use of lactational amenorrhoea method (LAM) among the population and separately among females able to use LAM at the time of the survey.

- Assessment of knowledge of LAM was affected by a change in the phrasing of the question in 2016, thus limiting comparability with previous surveys.

- The measurement of LAM use was based on selfreport which may result in underestimation or overestimation due to differences in understanding of LAM.

- The surveys did not collect information about reasons for non-use of LAM or about follow-on contraceptive methods.

including the transition to use of other modern contraceptive methods.

\section{INTRODUCTION}

Reducing adolescent pregnancy rates is an important public health issue in sub-Saharan Africa (SSA), where high fertility and unmet need for family planning (FP) persist. Estimates show that 21 million adolescents aged 15-19 years in developing countries become pregnant every year. ${ }^{12}$ Of these, 2.5 million are younger adolescents 12-15 years and at least 10 million are unintended pregnancies. $^{1}{ }^{2}$ The prevalence of adolescent first births in SSA is estimated at 50\%. ${ }^{1}$ As of 2019 about 218 million women in low-income and 
middle-income countries (LMICs) had an unmet need for $\mathrm{FP}^{3}{ }^{3}$ In SSA, $25 \%$ of women aged 15-49 years are estimated to have an unmet need for FP. ${ }^{4}$ In 2019 , $43 \%$ of adolescents in LMICs were estimated to have an unmet need for FP. ${ }^{3}$ Tackling the unmet need for FP among adolescents is critical especially in LMICs because it has significant implications on their reproductive health and well-being. ${ }^{5}$ Adolescent childbearing has been associated with multiple adverse health outcomes, ${ }^{67}$ and the literature also shows several challenges of the motherhood transition period for adolescents, which leave them disempowered with feelings of shame and embarrassment. ${ }^{8-10}$ Specifically, concern has been raised about the unmet need for FP among postpartum women. ${ }^{11}$ The acceptability and correct use of various FP methods among women during this period is affected by various sociocultural and structural factors. ${ }^{12} 13$

Lactational amenorrhoea method (LAM) is a recognised modern contraceptive method where postpartum amenorrhoeic women depend on the contraceptive effect of breast feeding within the first 6 months after childbirth. ${ }^{14}$ LAM provides $98 \%$ protection against pregnancy if (1) the woman's menstrual period has not returned since childbirth, (2) the baby is fully or nearly fully breastfed and (3) the baby is less than 6 months old. ${ }^{1415}$ The correct use of LAM provides an effective and affordable contraceptive option for breastfeeding women, while also providing an opportunity for linkage and transition of mothers to other FP methods and services. Furthermore, LAM use does not require replenishment of contraceptive supplies or a healthcare provider after appropriate LAM counselling is given. Therefore, LAM can play an important role in preventing unwanted pregnancies during the postpartum period and consequently maternal deaths. ${ }^{16}$ However, its effectiveness may be undermined by factors or practices that affect the three criteria, especially breast feeding. Evidence shows low breastfeeding rates, ${ }^{17} 18$ and a higher likelihood of exclusive breastfeeding (EBF) discontinuation before infants reach 6 months among adolescent mothers. ${ }^{19}$ A study of Nigerian adolescents found lower rates of early breastfeeding initiation and EBF compared with women 20-24 years. ${ }^{20}$ Education level, mode of delivery, antenatal care attendance and postnatal breastfeeding counselling are some of the factors influencing breastfeeding practices among adolescents. ${ }^{1820}$

Uganda has one of the highest total fertility rates (5.4 children per woman), maternal mortality rates of $336 / 100000$ live births, ${ }^{21}$ and the youngest population with $78 \%$ under 30 years, ${ }^{22}$ in the world. About $25 \%$ of adolescent girls in Uganda have started childbearing, with about 360000 teenage pregnancies occurring annually. ${ }^{21}{ }^{23}$ Evidence shows that over $40 \%$ of pregnancies among Ugandan adolescents are unintended, ${ }^{24}$ and there is an increasing occurrence of repeat adolescent births ( $<20$ years) estimated at $56 \%$, with a prevalence of short birth intervals of $5.4 \% .{ }^{25}$ Unmet need for child spacing among women with adolescent births or repeat adolescent births have also been reported. ${ }^{625}$ Lack of knowledge and access to general health services and youth-friendly FP care, in particular, are some of the key challenges affecting adolescent health in Uganda. ${ }^{26}$ Evidence on the use of LAM in adolescents in LMICs are still scarce. There is a need to better understand the duration, knowledge, and correct use of LAM as a postpartum FP method among adolescents. ${ }^{5}$

The main objective of this study was to assess the knowledge and use of LAM among adolescents in Uganda between 2006 and 2016 using nationally representative data from Demographic and Health Surveys (DHS).

\section{METHODOLOGY \\ Data}

This study is a secondary analysis of the cross-sectional data collected during Uganda DHS in 2006, 2011 and 2016. These are nationally representative household surveys carried out every 5 years. The DHS employs a stratified two-stage cluster sampling design to select participating households. In the first stage, enumeration areas (EAs) are selected and then the households are selected in the second stage from a complete listing of households. The 2016 Uganda Demographic and Health Survey (UDHS) included 697 EAs and a representative sample of 20880 households (30 per EA). The 2011 UDHS selected 405 EAs and a representative sample of 10086 households (all households in the selected EAs were included). In the 2006 UDHS, 321 EAs were selected and a representative sample of 9864 households were included (about 28 per EA). ${ }^{21} 2728$

All women of reproductive age (15-49 years) who are either permanent residents of the selected households or visitors who stayed in the household the night before the survey are eligible to be interviewed. The response rates (respondents interviewed/eligible respondents) for the eligible women in each of the three surveys were as follows: $97.0 \%$ (18 506/19 088) in 2016; $93.8 \%$ (8674/9247) in 2011; and 94.7\% (8531/9006) in 2006. Across all three surveys, response rates were higher in rural compared with urban areas. ${ }^{21} 2728$ The women interviewed provide, among others, self-reported information on their education, marital status, reproductive history, FP use, maternal health-seeking for recent live births and breastfeeding practices. Data were collected by trained data collectors using pretested tools.

\section{Study population}

Our analysis sample included women of reproductive age (15-49 years) at the time of each survey. The primary study population was adolescent girls aged 15-19 years, who were compared with young women aged 20-24 years and to all women of reproductive age 15-49 years. Within the sample, we also included a subgroup of adolescent girls and young women with a live birth in the 6 months before each survey as they are the population benefitting from LAM. The overall response rate of eligible women for the DHS surveys was generally over $90 \%$ (97.0\% in 
Table 1 Definitions of key study variables

\begin{tabular}{|c|c|c|c|}
\hline & $\begin{array}{l}\text { Indicator } \\
\text { (estimate) }\end{array}$ & Definition (numerator/denominator) & $\begin{array}{l}\text { Stratification by woman's age } \\
\text { group } \\
\text { (at time of survey) }\end{array}$ \\
\hline 1 & $\begin{array}{l}\text { Knowledge of LAM as FP } \\
\text { method among all women } \\
(\% \text { with } 95 \% \mathrm{Cl})\end{array}$ & Women who report ever hearing of LAM/all women & $\begin{array}{l}15-19.9 \\
20-24.9 \\
\text { All women } 15-49\end{array}$ \\
\hline 2 & $\begin{array}{l}\text { Knowledge of LAM among } \\
\text { eligible women } \\
\text { (\% with } 95 \% \mathrm{Cl} \text { ) }\end{array}$ & $\begin{array}{l}\text { Women with a child }<6 \text { months of age who report } \\
\text { ever hearing of LAM/all women with a child }<6 \\
\text { months of age }\end{array}$ & $\begin{array}{l}15-19.9 \\
20-24.9 \\
\text { All women } 15-49\end{array}$ \\
\hline 3 & $\begin{array}{l}\text { Current reported use of LAM } \\
\text { as FP method among all } \\
\text { women } \\
\text { (\% with } 95 \% \mathrm{Cl} \text { ) }\end{array}$ & $\begin{array}{l}\text { Women who report using LAM as their FP method at } \\
\text { time of survey/all women }\end{array}$ & $\begin{array}{l}15-19.9 \\
20-24.9 \\
\text { All women } 15-49\end{array}$ \\
\hline 4 & $\begin{array}{l}\text { Current reported use of LAM } \\
\text { as FP method among eligible } \\
\text { women }(\% \text { with } 95 \% \mathrm{Cl})\end{array}$ & $\begin{array}{l}\text { Women with a child }<6 \text { months of age who report } \\
\text { using LAM as their FP method at time of survey/all } \\
\text { women with a child }<6 \text { months of age }\end{array}$ & $\begin{array}{l}15-19.9 \\
20-24.9 \\
\text { All women } 15-49\end{array}$ \\
\hline 6 & $\begin{array}{l}\text { Passive use of LAM among } \\
\text { eligible women ( } \% \text { with } \\
95 \% \mathrm{Cl})\end{array}$ & $\begin{array}{l}\text { Women with a child }<6 \text { months of age who meet the } \\
\text { three LAM criteria but do not report using LAM/all } \\
\text { women with a child }<6 \text { months of age }\end{array}$ & $\begin{array}{l}15-19.9 \\
20-24.9 \\
\text { All women } 15-49\end{array}$ \\
\hline 7 & $\begin{array}{l}\text { Protection by LAM among all } \\
\text { women }(\% \text { with } 95 \% \mathrm{Cl})\end{array}$ & $\begin{array}{l}\text { Women who meet the three LAM criteria regardless of } \\
\text { whether they report the use of LAM or not/all women }\end{array}$ & $\begin{array}{l}15-19.9 \\
20-24.9 \\
\text { All women } 15-49\end{array}$ \\
\hline 8 & $\begin{array}{l}\text { Protection by LAM among } \\
\text { eligible women (\% with } \\
95 \% \mathrm{Cl} \text { ) }\end{array}$ & $\begin{array}{l}\text { Women with a child }<6 \text { months of age who meet the } \\
\text { three LAM criteria regardless of whether they report } \\
\text { the use of LAM or not/all women with a child }<6 \\
\text { months of age }\end{array}$ & $\begin{array}{l}15-19.9 \\
20-24.9 \\
\text { All women } 15-49\end{array}$ \\
\hline
\end{tabular}

FP, family planning; LAM, lactational amenorrhoea method.

2016, 93.8\% in 2011 and $94.7 \%$ in 2006). This suggests a non-response rate of about $3 \%-6 \%$. However, the response rates are not disaggregated by age group to represent the study population (15-19, 20-24).

\section{Definitions}

We estimated the following indicators capturing three dimensions of lactational amenorrhoea: (1) knowledge of LAM; (2) use of LAM-including reported, correct, passive and overall protection by lactational amenorrhoea; and (3) duration of postpartum amenorrhoea (PPA) (table 1).

Knowledge of LAM was defined as the respondent being aware of LAM as a method of FP, and was measured based on respondents' binary (yes, no) answer to 'Have you ever heard of lactational amenorrhea as a family planning method?' It should be noted that, in the 2016 survey, this question was followed with a probe that describes LAM further, that is, 'Up to 6 months after childbirth, before the menstrual period has returned, women use a method requiring frequent breastfeeding day and night'. This probe was not used in the
2006 and 2011 surveys. We assessed knowledge of LAM among all women and among eligible women who could have been using this method at the time of the survey (those with infants below 6 months of age at the time of each survey).

The use of LAM was based on the reported current use of lactational amenorrhoea as a FP method at the time of each survey (yes or no). This was measured by asking women whether they were doing anything or using any method to delay or avoid getting pregnant; and if so, what method they were using (multiple responses were allowed, eg, LAM and male condoms). We examined the use of LAM through four indicators:

1. Current use of LAM: women who reported using LAM as their method of FP at the time of the survey. We applied two denominators: all women and eligible women (those with infants below 6 months at the time of the survey).

2. Correct use of LAM: women who reported LAM use and met the three LAM criteria, among eligible wom- 
en (those with infants below 6 months at the time of the survey). The three criteria for correct use of LAM were (1) woman has a child $<6$ months of age at the time of the survey, (2) woman's menstrual period had not returned since the most recent birth and (3) her infant was being exclusively breast fed at the time of the survey. Exclusive breast feeding was defined as infants $<6$ months of age at the time of the survey who were fed exclusively with breastmilk, that is not given anything other than breastmilk in the 24 hours before the survey, except for oral medications.

3. Passive use of LAM: women meeting the three LAM criteria but who did not report LAM use, among eligible women (those with infants $<6$ months at the time of the survey).

4. Protection by LAM: women who met the three LAM criteria, regardless of whether they reported LAM use or not), among all women and eligible women.

\section{Duration of PPA}

PPA period was defined as the time to the resumption of the menstruation period following childbirth. This was captured by calculating the median duration in months using the child recode file, following the standard DHS method. ${ }^{29}$

\section{Other variables}

We used data on women's sociodemographic characteristics at the time of the surveys, including women's age in years, marital status, education status, place and region of residence and household wealth quintile. Marital status was categorised as 'never in union', currently in union/ living with a man, and formerly in union/living with a man. Education was categorised as no education, primary education, secondary education and higher education. Participants' place of residence was either urban or rural, and household wealth quintiles as produced by the DHS (we adapted wealth quintile categories for the 2006/2011, ie, poorest, poorer, middle, richer, richest). In the 2016 survey, Uganda had been divided into further regional units ( 15 subregions), which was an increase from the previous 9 and 10 used in the 2006 and 2011 surveys. For comparability, some subregions in 2016 were recategorised to have 10 regions as follows: West Nile (west Nile), North (Acholi+Lango), Karamoja (Karamoja), Western (Bunyoro + Tooro), East central (Busoga), Eastern (Teso + Bugisu + Bukedi), Central 2 (North Buganda), Southwest (Ankole + Kigezi), South Buganda (Central 1) and Kampala (Kampala).

\section{Statistical analysis}

Analysis was conducted using STATA V.14 (StataCorp, Texas, USA). We utilised the syyset command in STATA to adjust for the sampling design used and for non-response, using DHS instructions and variables provided to capture stratification, clustering and individual sampling weights. Descriptive statistics including frequencies and percentages were used to summarise categorical data while
Table 2 Sample size of women according to age group at the time of each survey and recent birth history, by survey

\begin{tabular}{|c|c|c|c|}
\hline Category & 2006 & 2011 & 2016 \\
\hline $\begin{array}{l}\text { All female respondents (15-49 } \\
\text { years) }\end{array}$ & 8531 & 8674 & 18506 \\
\hline Adolescents (15-19 years) & 1948 & 2026 & 4276 \\
\hline $\begin{array}{l}\text { Adolescents with a live birth } \\
<6 \text { months before the survey }\end{array}$ & 367 & 376 & 837 \\
\hline Young women (20-24 years) & 1662 & 1666 & 3782 \\
\hline $\begin{array}{l}\text { Young women with a live birth } \\
<6 \text { months before the survey }\end{array}$ & 1291 & 1225 & 2831 \\
\hline
\end{tabular}

continuous data (duration of PPA) was expressed in terms of median and IQR. We computed the unweighted numbers of women for the given variable and the weighted percentages and 95\% CI. For all denominators using eligible women (with infants below 6 months at the time of the survey), we only included women with infants who were alive at the time of the survey due to breast feeding as a criterion for correct LAM use. In the computation of reported use of LAM at the time of the survey, we assumed that all women who did not report using LAM were indeed not using LAM (missing values were recorded as 0 ). There was no missing data on other key variables for the study samples included in the analysis.

\section{Patient and public involvement}

Patients or the public were not involved in the design, or conduct, or reporting, or dissemination plans of this research.

\section{RESULTS \\ Sociodemographic characteristics of the study samples}

A total of 1948 (2006), 2026 (2011) and 4276 (2016) adolescents (15-19 years) and 1662 (2006), 1666 (2011) and 3782 (2016) young women (20-24 years) were included (table 2). Across the decade, primary education was the highest level attained in both adolescents (at an average $65.4 \%)$ and young women $(\approx 55.0 \%)$ (table 3 ). Approximately $77.4 \%$ of adolescents had never been married as compared with approximately $23.8 \%$ in the young women. Table 3 also shows an increasing trend in the proportion of adolescents $(17.7 \%$ to $24.3 \%)$ or young women $(22.0 \%$ to $29.9 \%)$ living in urban areas.

\section{Knowledge of LAM}

Knowledge of LAM as a FP method was analysed for two categories of women; all women and eligible women (who had a child $<6$ months at the time of the survey). Between 2006 and 2016, knowledge of LAM among all and eligible adolescent girls increased. Among all adolescents, knowledge of LAM increased from $3.7 \%$ (95\% CI: $2.7 \%$ to $5.0 \%$ ) in 2006 to $36.9 \%$ (95\% CI: $35.0 \%$ to $38.9 \%$ ) in 2016; while among the eligible adolescents, it increased from $6.0 \%$ (95\% CI: $3.5 \%$ to $13.8 \%)$ to $56.7 \%$ (95\% 
व̊

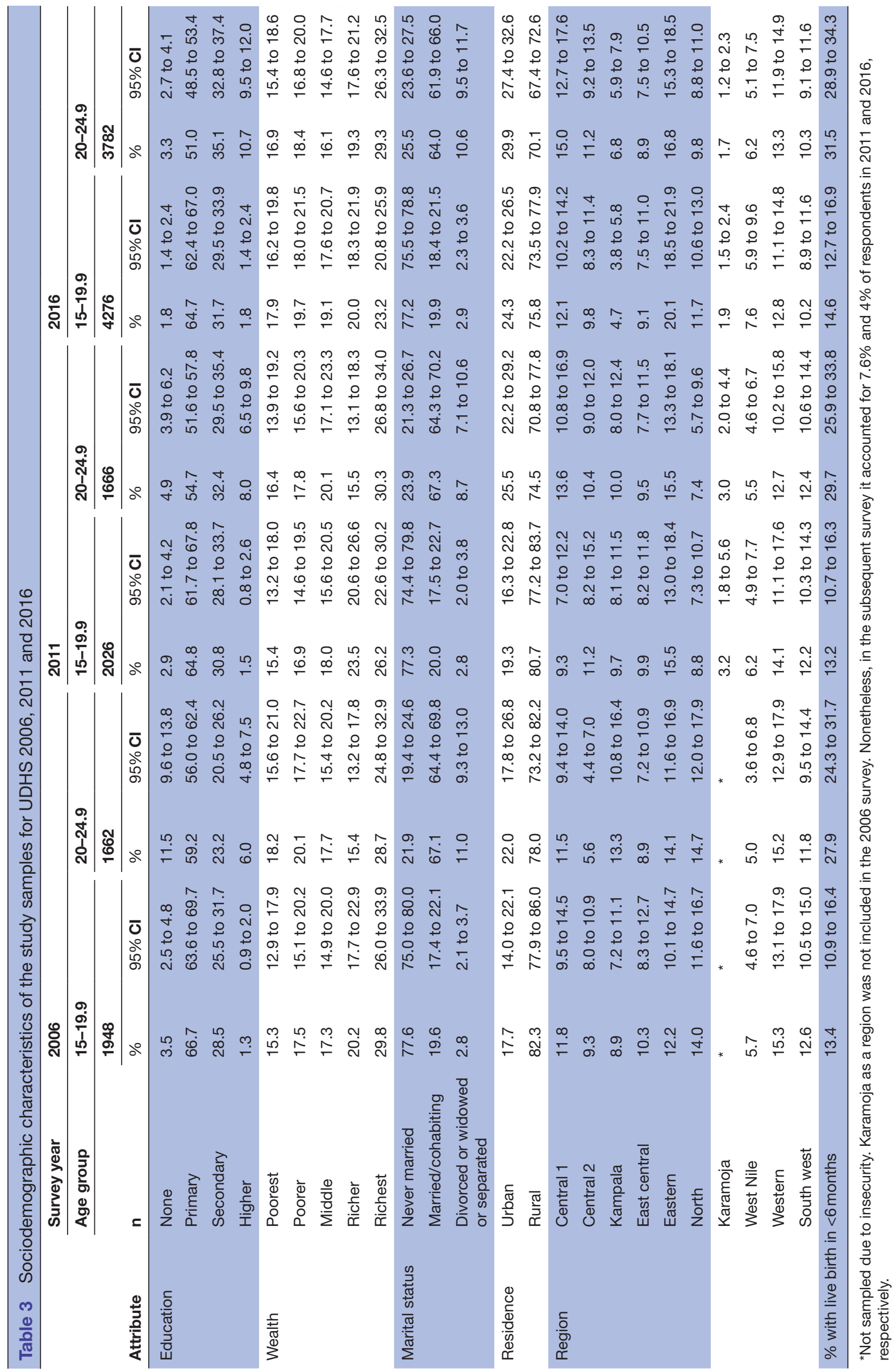


CI: $49.2 \%$ to $63.8 \%$ ), respectively (table 4 ). Compared with young women, knowledge of LAM among all or eligible women was generally lower among the adolescents. Among eligible young women, knowledge of LAM increased from $9.7 \%$ (95\% CI: $6.2 \%$ to $14.9 \%$ ) in 2006 to 64.1\% (95\% CI: $58.7 \%$ to $69.2 \%$ ) in 2016 .

\section{Use of LAM}

We determined the use of LAM using four broad indicators: current reported use, correct use, passive use of LAM and protection by LAM. The overall use of LAM over the 10 years was low among adolescents, young women and all women of reproductive age. The overall current reported use or correct use of LAM was less than $2 \%$ (table 4 ). The percentage of eligible adolescents or young women correctly using LAM was lower than the percentage who reported using LAM as their FP method. Among eligible women, the current reported use of LAM in adolescents was $1.3 \%$ (95\% CI: $0.4 \%$ to $3.8 \%$ ) in 2016 as compared with $0.7 \%$ (95\% CI: $0.2 \%$ to $1.9 \%)$ in young women; while the correct use of LAM in 2016 was $0.9 \%$ (95\% CI: $0.2 \%$ to $3.5 \%)$ in adolescents compared with $0.5 \%(95 \%$ CI: $0.1 \%$ to $1.6 \%$ ) in young women. Table 4 further shows that across the three surveys, the percentage of eligible women passively using LAM was higher compared with those reporting intentional LAM use $(>50 \%$ of eligible women in all surveys and age groups). Also, the passive use of LAM decreased among all age groups over the review period. Among adolescent girls, passive LAM use decreased from 76.4\% (95\% CI: $66.5 \%$ to $84.0 \%$ ) in 2006 to $56.3 \%$ (95\% CI: $48.8 \%$ to $63.6 \%$ ) in 2016 , compared with young women among whom it decreased from $84.9 \%$ (95\% CI: $78.8 \%$ to $89.5 \%)$ to $56.9 \%$ (95\% CI: $52.0 \%$ to $61.6 \%$ ), respectively. Between 2006 and 2016, the percentage of eligible women protected by LAM decreased across all age groups. As of 2016 at least $50 \%$ of women eligible for LAM were indeed protected by LAM in all three age groups, more so among all women of reproductive age at $62.0 \%$ (95\% CI: $58.9 \%$ to $64.9 \%)$. The percentage of eligible adolescents protected by LAM decreased from $76.4 \%$ (95\% CI: $66.5 \%$ to $83.99 \%$ ) in adolescents in 2006 to $57.2 \%$ (95\% CI: $49.5 \%$ to $64.6 \%$ ) in 2016, as compared with young women where it decreased from $84.9 \%$ (95\% CI: $78.8 \%$ to $89.5 \%$ ) in 2006 to $57.3 \%$ (95\% CI: $52.5 \%$ to $62.0 \%$ ) in 2016 (table 4$)$.

\section{Duration of PPA}

Over the 10-year period, the median duration of PPA declined among both adolescents and young women who had had a live birth in the 3 years preceding each survey (figure 1). Among the adolescents, the median duration of PPA decreased from 8.3 months in 2006 to 6.9 months in 2016, while in young women it decreased from 11.2 months to 8.0 months, respectively. Across all age groups, the median duration of PPA was lowest among adolescents. The median duration of PPA in 2016 was 1.1 months shorter among adolescents compared with young women.

\section{DISCUSSION}

This study explored the knowledge and use of lactational amenorrhoea as a FP method among adolescents in Uganda. The findings indicate that nearly $60 \%$ of eligible adolescents in 2016 had knowledge about LAM, and there was an increase in the percentage of adolescents with knowledge of LAM in the examined period. The reported and correct use of LAM among eligible adolescents was very low, and there was a high but declining prevalence of passive LAM use. The results also show a decrease in the median duration of PPA among adolescents between 2006 and 2016. We compared knowledge and use of LAM among adolescents to levels among young women and all women in reproductive age. On the most recent survey, we found that knowledge of LAM was lower among adolescents compared with the other groups, but reported use was similarly low and passive use comparably high (near universal) across the three age groups.

We found large increases in knowledge of LAM among all and eligible adolescents, especially between 2011 and 2016. Part of this increase may be attributed to changes in the measurement of LAM knowledge in 2016 where a description of LAM was read out to the respondents by survey enumerators, which was not the case in the years before. While some views have previously considered this as a quality concern resulting in misreporting by women, other analyses have supported the inclusion of the LAM description, as higher proportions of self-reported LAM users who correctly practised LAM were observed in surveys with the description. ${ }^{30}$ Any true increase in levels of knowledge about LAM may be attributed to various efforts that have been implemented over time by the Ugandan government including free primary education, FP initiatives including the use of community health workers and promoting the provision of adolescent and youth-friendly services. ${ }^{24}$ The percentage of eligible adolescents who were aware of LAM in this study was higher than what has been reported among women of reproductive age in other SSA countries. ${ }^{113132}$ This may be explained by differences in the methods for determining knowledge of LAM. For example, studies by Abraha $e t a l^{11}$ and Ekpenyong et $a l^{32}$ went beyond the DHS approach and included an assessment of respondents' understanding of the three criteria for LAM practice. Regardless, the observed increase in knowledge may result in better attitudes towards and acceptability of LAM as an effective contraceptive method, which would contribute to increase adoption. But this would be dependent on the appropriateness of the information to which adolescents are exposed and their ability to apply it correctly, among other factors.

Findings from this study show very low percentages of eligible adolescents reporting the use of LAM as their primary FP method, and those that were correctly using it. The low prevalence of reported LAM use may partly be explained by methodological limitations posed by the DHS where if a woman reports use of both LAM and other modern methods, the most effective method 


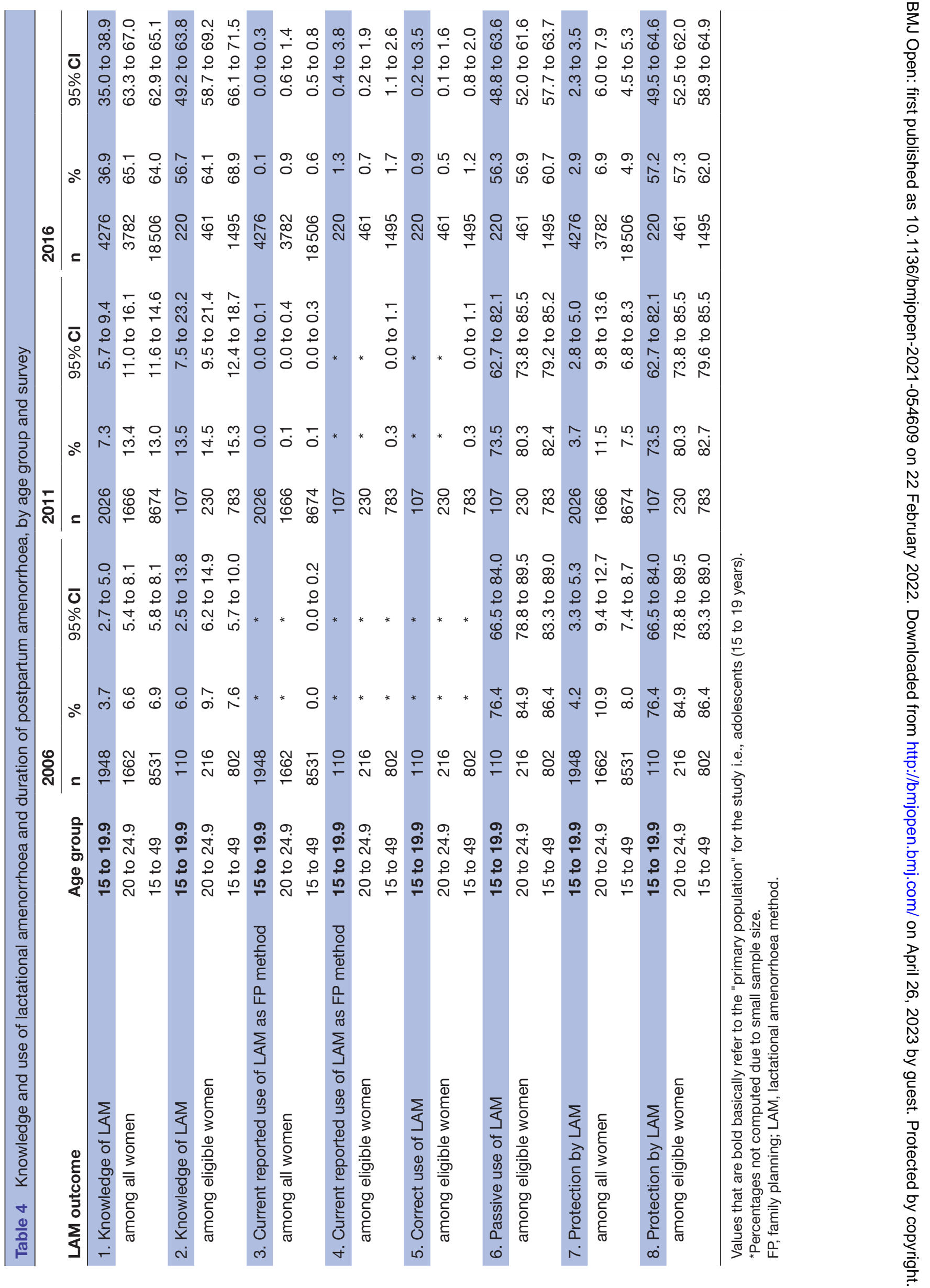




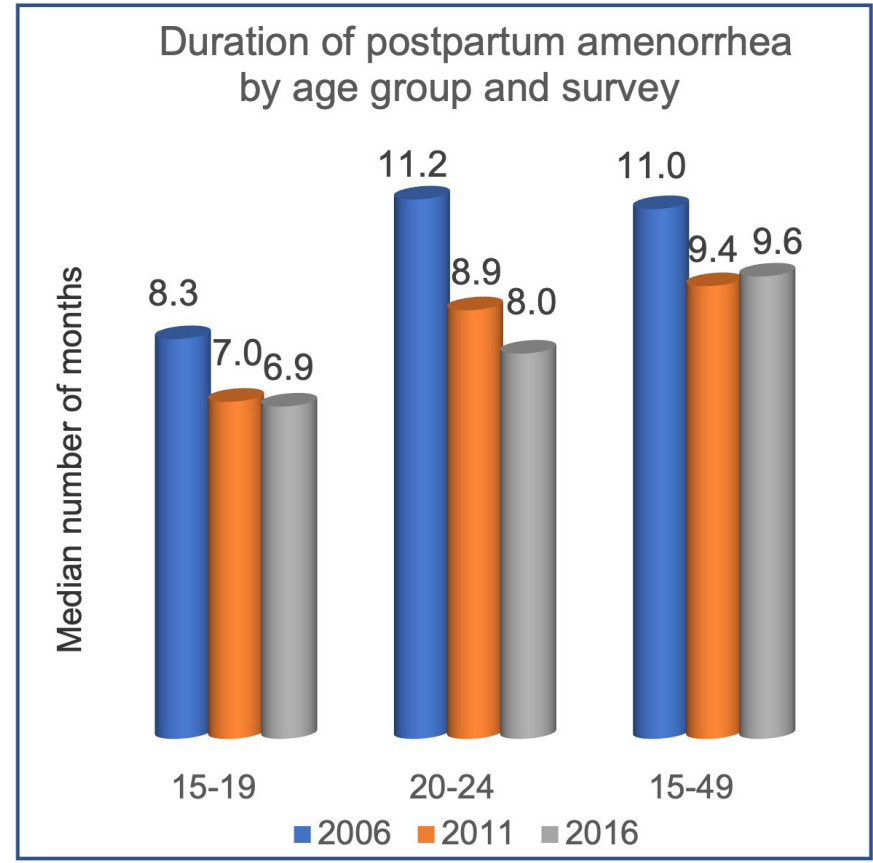

Figure 1 Duration of postpartum amenorrhoea by age group and survey.

is recorded and the woman is not recorded as a LAM user. $^{30}$ The use of other FP methods besides LAM during the first 6 months after childbirth has been reported. ${ }^{33}$ This may explain the observed high proportion of women who were passively using LAM (meet the LAM criteria but do not report LAM use). The study findings relate to previous studies that also show a low prevalence of LAM use among women of reproductive age in general, ${ }^{30}$ and adolescents in particular. ${ }^{5}$ Low correct use of LAM is a result of not fulfilling one or more of the three criteria, which also influence the effectiveness of LAM as an FP method. This would mean that if new adolescent mothers are not correctly using LAM and they are not using any other FP methods within the first 6 months after childbirth, they would be at higher risk of becoming pregnant again. This would also vary based on factors like sexual activity or access to clinical or social support during this period. In other studies, violation of the exclusive breast feeding and PPA criteria have been reported to be the primary factors affecting the correct use of LAM. ${ }^{14} 34$ This is particularly important in adolescents among whom, early initiation and exclusive breast feeding has been reported to be low, with a higher likelihood of discontinuation. 1920

PPA is one of the key determinants for correct LAM use and its effectiveness. The study findings showed a decrease in the median duration of PPA among adolescents from 8.3 (2006) to 6.9 (2016). The resumption of menses is a commonly used reported determinant of FP use among postpartum women, ${ }^{35}$ yet variably understood as reported by Cooper et $a l^{36}$ who found misconceptions about the return of fecundity in Tanzania. ${ }^{36}$ The decreasing duration of PPA points to the need to strengthen postpartum FP among adolescents, as the risk of becoming pregnant may be higher in this subpopulation. The review by Figaroa and colleagues noted wide variation in PPA duration among adolescents in $\mathrm{LMICs}^{5}$; while a study in India among women with at least one live birth reported a lower duration of PPA ( 5.7 months) than what was found in the present study. ${ }^{37}$ Breastfeeding practices have also been linked to a shorter total duration of PPA. ${ }^{37}$ According to the authors, the risk of resumption of menses decreases with the increasing duration of breast feeding. This may explain the decreasing duration of PPA among adolescents and why it was lower compared with young women in this study.

\section{Strengths and Limitations}

This study benefitted from three rounds of highly comparable nationally representative data collected over 10 years in Uganda to provide an understanding of patterns of LAM use among adolescents. We constructed several indicators of LAM knowledge and use, with sensitivity to the population under consideration (ie, denominators). Nonetheless, this study has limitations. First, it was not possible to investigate factors associated with LAM knowledge or use among adolescents because of the small sample size to allow any meaningful associations. Such information would help inform strategies to improve the use of LAM in this key subpopulation. The findings are also limited by the use of self-reported data on the use of LAM and its criteria especially exclusive breast feeding and return of menses. Correct/accurate reporting on such variables is rather subjective and is affected by the individual's understanding which is often limited. Also, the assessment of knowledge of LAM in the surveys is limited to a single variable and may therefore not provide proper indication of the understanding of LAM among adolescents. The surveys also did not collect information about reasons for non-use of LAM or about follow-on contraceptive methods. Further qualitative studies can help elucidate the understanding and considerations for use of LAM in this important population segment.

\section{CONCLUSIONS}

There is increasing awareness about LAM but, the reported and correct use of LAM is low among adolescents with a live baby under 6 months of age in Uganda. There is need to improve uptake of contraceptive methods especially in postpartum adolescents through targeted counselling and educational programmes. This will go a long way in not only reducing their short-interpregancy intervals but improving their health and well-being including that of their children. Further, additional research is needed to better understand the dynamics of correct LAM use and transition to other FP methods among adolescent mothers.

\section{Author affiliations}

${ }^{1}$ School of Public Health, Makerere University College of Health Sciences, Kampala, Uganda

${ }^{2}$ Department of Public Health, Institute of Tropical Medicine, Antwerpen, Belgium 
${ }^{3}$ Health Support Initiatives, Kampala, Uganda

${ }^{4}$ Division of Global Health, Karolinska Institutet, Stockholm, Sweden

\section{Twitter Solomon T Wafula @SolomonWafula24}

Acknowledgements CB and PB would like to thank the Institute of Tropical Medicine in Belgium for the training that contributed to the development of this paper. We would also like to convey our thanks to the Demographic and Health Survey programme for granting access to the survey datasets which were used in this study.

Contributors $\mathrm{CB}$ and $\mathrm{PB}$ share first authorship and contributed equally to this paper. $\mathrm{CB}$ and $\mathrm{PB}$ conceptualised the study, conducted data analysis and developed the manuscript. LB provided analysis guidance and supported the conceptualisation process and data analysis. CB, PB and LB wrote the first manuscript draft. STW supported data analysis and participated in manuscript review. PW provided technical guidance to the manuscript development process. All authors reviewed the manuscript and approved the final manuscript. CB is acting as the guarantor.

Funding The authors have not declared a specific grant for this research from any funding agency in the public, commercial or not-for-profit sectors.

Competing interests None declared.

Patient and public involvement Patients and/or the public were not involved in the design, or conduct, or reporting or dissemination plans of this research.

\section{Patient consent for publication Not applicable.}

Ethics approval Data used for the analysis of this paper were obtained with permission from the Demographic and Health Survey (DHS) programme of the US Agency for International Development. The DHS receives government permission, uses informed consent, and assures respondents of confidentiality. The procedures and questionnaires for DHS surveys are reviewed and approved by the ICF International Institutional Review Board (IRB). In addition, ethical approval is obtained from a national ethical review board and local authorities before the surveys are conducted. Before each interview, an informed consent statement providing details on purpose of interview, expected duration, procedures, potential risks and benefits, voluntary participation and confidentiality is read to each respondent and verbal consent is sought. For adolescents, a parent or guardian provides consent prior to their participation in the survey. The data collection procedures are described at length in each survey report, we provide the references to these publicly available materials. We did not require an ethics approval for this study since it involved analysis of only secondary non-identifiable data, which is publicly available to registered users from the online data repositiories.

Provenance and peer review Not commissioned; externally peer reviewed.

Data availability statement Data are available in a public, open access repository. Data are available for research purposes on www.dhsprogram.com after registration.

Open access This is an open access article distributed in accordance with the Creative Commons Attribution Non Commercial (CC BY-NC 4.0) license, which permits others to distribute, remix, adapt, build upon this work non-commercially, and license their derivative works on different terms, provided the original work is properly cited, appropriate credit is given, any changes made indicated, and the use is non-commercial. See: http://creativecommons.org/licenses/by-nc/4.0/.

\section{ORCID iD}

Catherine Birabwa http://orcid.org/0000-0003-2916-9275

\section{REFERENCES}

1 Neal S, Matthews Z, Frost M, et al. Childbearing in adolescents aged 12-15 years in low resource countries: a neglected issue. New estimates from demographic and household surveys in 42 countries. Acta Obstet Gynecol Scand 2012;91:1114-8.

2 World Health Organization. Adolescent pregnancy, 2020. Available: https://www.who.int/news-room/fact-sheets/detail/adolescentpregnancy

3 Sully Eet al. Adding it up: investing in sexual and reproductive health 2019, 2020.

4 Ahinkorah BO, Ameyaw EK, Seidu A-A. Socio-Economic and demographic predictors of unmet need for contraception among young women in sub-Saharan Africa: evidence from cross-sectional surveys. Reprod Health 2020;17:163.
5 Figaroa MNS, Bellizzi S, Delvaux T, et al. Lactational amenorrhoea among adolescent girls in low-income and middle-income countries: a systematic scoping review. BMJ Glob Health 2020;5:e002492.

6 Amongin D, Benova L, Nakimuli A, et al. Trends and determinants of adolescent childbirth in Uganda- analysis of rural and urban women using six demographic and health surveys, 1988-2016. Reprod Health 2020;17:74.

7 Burke HM, Santo LD, Bernholc A, et al. Correlates of rapid repeat pregnancy among adolescents and young women in Uganda. Int Perspect Sex Reprod Health 2018;44:11-18.

8 Erfina E, Widyawati W, McKenna L, et al. Adolescent mothers experiences of the transition to motherhood: an integrative review. Int J Nurs Sci 2019;6:221-8.

9 Mangeli M, Rayyani M, Cheraghi MA, et al. Exploring the challenges of adolescent mothers from their life experiences in the transition to motherhood: a qualitative study. J Family Reprod Health 2017;11:165-73.

10 Ngum Chi Watts MC, Liamputtong P, Mcmichael C. Early motherhood: a qualitative study exploring the experiences of African Australian teenage mothers in greater Melbourne, Australia. BMC Public Health 2015;15:873.

11 Abraha TH, Teferra AS, Gelagay AA, et al. Knowledge and associated factors of lactational amenorrhea as a contraception method among postpartum women in Aksum town, Tigray region, Ethiopia. BMC Res Notes 2018:11:641.

12 Coomson JI, Manu A. Determinants of modern contraceptive use among postpartum women in two health facilities in urban Ghana: a cross-sectional study. Contracept Reprod Med 2019;4:17.

13 Joshi AK, Tiwari DP, Poudyal A, et al. Utilization of family planning methods among postpartum mothers in Kailali district, Nepal. Int $J$ Womens Health 2020;12:487-94.

14 Van der Wijden C, Manion C. Lactational amenorrhoea method for family planning. Cochrane Database Syst Rev 2015:CD001329.

15 World Health Organization. Postpartum family planning: essential for ensuring health of women and their babies, 2018. Available: https:// www.who.int/reproductivehealth/topics/family_planning/worldcontraception-day-2018/en/

16 Alege SG, Matovu JK, Ssensalire S, et al. Knowledge, sources and use of family planning methods among women aged 15-49 years in Uganda: a cross-sectional study. Pan Afr Med J 2016;24:39.

17 Rahman A, Nomani D, Taneepanichskul S. Trends and determinants of EBF among adolescent children born to adolescent mothers in rural Bangladesh. Int J Environ Res Public Health 2020;17:9315.

18 Yılmaz E, Yllmaz Z, Isık H, et al. Factors associated with breastfeeding initiation and exclusive breastfeeding rates in Turkish adolescent mothers. Breastfeed Med 2016;11:315-20.

19 Jara-Palacios Miguel Á, Cornejo AC, Peláez GA, et al. Prevalence and determinants of exclusive breastfeeding among adolescent mothers from Quito, Ecuador: a cross-sectional study. Int Breastfeed $J$ 2015;10:33

20 Benova L, Siddiqi M, Abejirinde $\mathrm{I}-\mathrm{OO}$, et al. Time trends and determinants of breastfeeding practices among adolescents and young women in Nigeria, 2003-2018. BMJ Glob Health 2020:5:e002516.

21 UBOS, U.B.o.S. and ICF. Uganda demographic and health survey 2016: key indicators report. Maryland, USA: UBOS ICF, 2017.

22 UBOS, U.B.o.S.. The National Population and Housing Census 2014 - National Analytical Report. Kampala, Uganda: UBOS, 2017.

23 Ministry of Health, U.. Reproductive, maternal, newborn, child and adolescent health Sharpened plan for Uganda 2016/17 - 2019/20. Kampala, Uganda, 2016

24 Nalwadda G, Namutebi M, Volgsten $\mathrm{H}$. Health care providers' perceptions of family planning and contraception education for adolescents in Kampala, Uganda - A qualitative study. Sex Reprod Healthc 2019;21:15-20.

25 Amongin D, Nakimuli A, Hanson C, et al. Time trends in and factors associated with repeat adolescent birth in Uganda: analysis of six demographic and health surveys. PLoS One 2020;15:e0231557.

26 Atuyambe LM, Kibira SPS, Bukenya J, et al. Understanding sexual and reproductive health needs of adolescents: evidence from a formative evaluation in Wakiso district, Uganda. Reprod Health 2015:12:1-10.

27 UBOS, U.B.o.S. and I.I.I. ICF. Uganda Demographic and Health Survey 2011. UBOS and Calverton, Mayrland: Kampala, Uganda, 2012.

28 UBOS, U.B.o.S. and M.I. Inc. Uganda Demographic and Health survey 2006. Calverton, Maryland, USA: UBOS and Macro International Inc., 2007.

29 Tesfayi G, Shea R, Vinod M. Contraceptive Use, Breastfeeding, Amenorrhea and Abstinence During the Postpartum Period: An Analysis of Four Countries. DHS Analytical Studies. 14, 2008. 
30 Fabic M, Choi Y. Measuring use of the lactational amenorrhea method through the demographic and health surveys: data quality and implications. annual meeting of the Population Association of America, New Orleans, 2013.

31 Alvey J. Measuring the use of the lactational amenorrhea method as a postpartum family planning method in urban Nigeria: challenges in measurement and recommendations for future MIYCN-FP integrated programs, 2015.

32 Ekpenyong CEet al. Lactational amenorrhoea method of contraception: an in-depth study of awareness, knowledge and practice by breast feeding mothers with unintended pregnancies. International Journal of Medicine and Medical Sciences 2013;5:6-13.

33 Afifi M. Lactational amenorrhoea method for family planning and women empowerment in Egypt. Singapore Med J 2007;48:758-62.
34 Sipsma HL, Bradley EH, Chen PG. Lactational amenorrhea method as a contraceptive strategy in niger. Matern Child Health $J$ 2013;17:654-60.

35 Gahungu J, Vahdaninia M, Regmi PR. The unmet needs for modern family planning methods among postpartum women in subSaharan Africa: a systematic review of the literature. Reprod Health 2021;18:1-15.

36 Cooper CM, Kavle JA, Nyoni J, et al. Perspectives on maternal, infant, and young child nutrition and family planning: considerations for rollout of integrated services in Mara and Kagera, Tanzania. Matern Child Nutr 2019;15 Suppl 1:e12735.

37 Singh NS, Singh NS, Narendra RK. Postpartum amenorrhoea among Manipuri women: a survival analysis. J Health Popul Nutr 2012;30:93. 